\title{
INDIGENISMO Y MARGINACIÓN DE LOS NEGROS EN AMÉRICA LATINA
}

\author{
Victorien Lavou Zoungho \\ Centre d'Études et de Recherches Sociocritiques, \\ Montpellier, Francia
}

Quisiera, primero, aclarar dos aspectos:

1. La cuestión de la objetivación de una realidad en la cual no estoy directamente involucrado. Escribo sobre América Latina desde Francia, desde Europa. Yo dudo que la distancia en sí sea, como se ha creído siempre, necesariamente una garantía para una mayor "objetividad científica". Muchas veces los que escribimos "desde afuera" nos conf rontamos con el problema de las inevitables transformaciones de la realidad que pretendemos examinar. Por lo cual, y con esto aclaro el segundo punto:

2. Lo que voy a presentar no es sino un intento, el esbozo de un trabajo venidero. No les voy, entonces, a proponer conclusiones terminantes. Por el contrario, espero que mi problemática suscite interés y que pueda beneficiarme de sus observaciones para corregir, matizar y, como no, afianzar mejor tal o cual aspecto de mi trabajo.

Intentaré mostrar cómo el indigenismo (que considero como un conjunto contradictorio y conflictivo de prácticas y discursos) en su proyecto de integración económica y de valoración cultural de los indios, contribuyó indirectamente a acentuar la exclusión de los negros en América Latina. 
Quisiera, desde luego, indicarles que no me voy a meter en el debate relativo al alcance y la significación de las acciones indigenistas. Muchos estudios valiosos existen sobre el particular ${ }^{1}$. Lo que me parece totalmente rezagado, digamos ocultado, es la problemática que mencioné (la indirecta exclusión de los negros).

Mi punto de arranque lo constituye, pues, la experiencia indigenista de dos países donde durante largo tiempo se observó una voluntad política de integración de los indios. Se trata de México y de Perú. Esos dos países se distinguieron por la creación de centros indigenistas cuyo objetivo proclamado era elaborar diversos programas encaminados hacia la "peruanización" y la "mexicanización" de los indios. Esos centros estaban, por lo general, dirigidos y animados por intelectuales. Entre otros, antropólogos, sociólogos, etnólogos, historiadores y lingüistas. El Estado controlaba las orientaciones de las actividades de los centros indigenistas.

En 1940, se celebró en Pátzcuaro (México) el primer Congreso Indígena Interamericano. Los países representados, aparte de denunciar la gran marginación de los indios de los circuitos socioeconómicos nacionales, abogaron por una mejor coordinación de los esfuerzos que se hacían para concretar la integración de los indios y, por lo tanto, su real reconocimiento como sujetos de las naciones latinoamericanas. Así por lo menos lo planteó Lázaro Cárdenas en su discurso inaugural:

Ya nadie pretende una resurrección de los sistemas indígenas precortesianos o el estancamiento incompatible con las corrientes de la vida actual. Lo que se debe sostener es la incorporación a la cultura universal del indio, es decir, el desarrollo pleno de todas las potencias y facultades naturales de la raza... ${ }^{2}$.

1. Ver por ejemplo la obra colectiva, De eso que llaman Antropología mexicana (México: Editorial Nuevo Tiempo, 1970).

2. Fragmento del discurso de Cárdenas en el primer Congreso Indígena Interamericano celebrado el 14 de abril de 1940 en México, citado por Jesús Silva Herzog, Lázaro Cárdenas, su pensamiento económico, social y político (México: Nuestro Tiempo, 1975) 127. 
Verdadero programa político que coloca al indio, como entidad colectiva, en el centro de las preocupaciones. La voluntad de emancipar y de universalizar al indio que aparece en el discurso de Cárdenas ha sido una constante en Latinoamérica. Es en todo caso anterior al congreso de Pátzcuaro. Por lo que se refiere a México, Guillermo Bonfil llama nuestra atención sobre el uso político e ideológico de la figura del indio:

A la revolución mexicana de 1910 , sin duda, se debe el haber privilegiado la imagen india como uno de los principales símbolos del nacionalismo oficial... El arte auspiciado por los gobiernos de la Revolución, sobre todo entre los años veinte y los cuarenta, tuvo un marcado aspecto nacionalista. Hubo, pues, que volver a las raíces ${ }^{3}$.

El indio deviene así lo que otorga una legitimidad transcendente no sólo a la burguesía mexicana (en su lucha contra la oligarquía terrateniente) sino también a los intelectuales que por esos tiempos ingresaban como fuerza social en el escenario político nacional. O sea, la figura del indio constituye un objeto donde se invierten intereses políticos y simbólicos.

En Perú se dio casi el mismo fenómeno, al menos por lo que se refiere a los intelectuales en busca de un reconocimiento social. Antonio Cormejo Polar, el gran crítico peruano, señala en ef ecto que, en los años 1920-1940, se notó en Perú una evidente preocupación por el indio entre los intelectuales. En numerosos estudios/trabajos, interrogaban la articulación (posible o no) del vivir indio con el proceso de modernización capitalista (industrialización, urbanización, migraciones, etc.) en el cual su país parecía irremediablemente sumido ${ }^{4}$.

3. Guillermo Bonfil Batalla, México profundo. Una civilización negada (México: Grijalbo, 1990) 89.

4. He aquí algunos de esos trabajos: Cuentos andinos (1920) de López Albujar; Siete ensayos de interpretación de la realidad peruana (1928) de José Carlos Mariátegui; El antiimperialismoy el APRA (1936) de Víctor Raúl Haya de la Torre; Del ayllu al cooperativismo socialista (1936) de Hidelbrando Castro Pozo. 
El hecho de que, tanto en México como en Perú, la figura del indio se haya convertido en una apuesta simbólica, no nos autoriza sospechar, en todo caso, cuestionar (¿quiénes somos?) el compromiso positivo de algunos intelectuales a favor de los indios. Este compromiso procede, de manera general, de una identificación política.

El indigenismo, fuese oficial o marginal (no ligado directamente al Estado), plantea al indio como el objeto exclusivo de sus preocupaciones. Lo cual, diríase, resulta perfectamente legítimo. Sin embargo deberíamos también reconocer que ese mismo afán de "desagraviar" a los indios contribuyó indirectamente a ocultar todavía más la presencia y las reivindicaciones de los negros (y de otras minorías) en los países que desarrollan una política indigenista.

El discurso sobre los indios llegó a ser de facto el discurso privilegiado en la política e incluso en las ciencias sociales. El discurso indigenista viene así a quitarles legitimidad a los posibles discursos de, o sobre, otras minorías como los negros o los asiáticos.

Sería descaminado volver aquí sobre la génesis de la presencia de los negros en América Latina; muchos estudiosos se han consagrado ya a ello. No obstante, me parece sumamente importante impugnar el argumento pertinaz que se perfila en unos de esos estudios y según el cual los "escasos" años de presencia de los negros serían, al fin y al cabo, insignificantes si los comparamos con las remotísimas civilizaciones de los indios.

Ustedes se habrán dado cuenta de que ese mismo argumento de la duración nunca se esgrime cuando se aplica a la presencia de los conquistadores españoles. De hecho la herencia española es no sólo reconocida sino plenamente reivindicada y asumida por toda América Latina. Una buena ilustración de esto tal vez sea la celebración del Día de la Raza.

En el fondo, se trataría de acabar de una vez con esas opiniones que, al enfocarse sobre la supuesta inferioridad de las civilizaciones africanas con respecto a las precolombinas, convalidan visiones reductoras e intolerantes que rehúsan ver a los negros como portadores 
de civilización y de historia. Desde su perspectiva, los negros no pudieron (y no pueden) marcar significativamente la historia de América Latina.

Desafortunadamente, esta última consideración es todavía ampliamente difundida en América Latina. La encontramos, por ejemplo, en la pluma de José Carlos Mariátegui, uno de los más reconocidos precursores del indigenismo peruano. En sus Siete ensayos de interpretación de la realidad peruana sostiene que la participación de los negros en la cultura nacional peruana es nula, insignificante. Más aún, los negros (por su "sensualidad", sus "supersticiones" y "primitivismo") pudieron ser un factor de disolución de esa misma cultura ${ }^{5}$.

Es de temer que esa asombrosa declaración sintetice y a la vez actualice todo un imaginario colectivo con respecto a los negros de América Latina y de Perú en particular. Al colocar (y por lo tanto condenar) a los negros en el paradigma de la barbarie, el pensador marxista peruano elude al mismo tiempo la cuestión de su reconocimiento como entero su jeto latinoamericano, así como la de la aceptación de su herencia.

Me consta, sin embargo, que este debate se clausuró muy rápidamente. A este respecto, Cuba, Brasil y Venezuela, por razones obvias, parecen constituir unas excepciones en el silencio generalizado y consensual con respecto a los negros. Lo que quiero enfatizar es que esos países dan la impresión de asumir la herencia negra aun, reconozcámoslo, con contradicciones a veces profundas. Se sabe, por ejemplo, que en Cuba la población carceral es casi exclusivamente negra mientras que la universidad es en su mayoría blanca ${ }^{6}$. En el mismo Brasil dicen que:

Los brasileños aceptan que se diga que Brasil es un país negro, pero lo que no aceptan es que se diga que es un país de negros.

5. Mariátegui, 342.

6. Francis Pisani, «Blessure ouverte au coeur du régime, Cuba confronté à la question noire», en Le Monde Diplomatique (Septembre, 1992) 10-11. 
Culturalmente, africanos, sí; país de cafres, no. Brasil asume, es verdad su raíz africana, pero esto no quiere decir que no subsista el racismo ni la segregación social del negro: ¡aunque bailen el mismo samba, blancos y negros lo bailan aparte! ${ }^{7}$

En la conmemoración del quinto centenario del hecho colonial español se evidenció una vez más que los negros seguían siendo los verdaderos ausentes de la historia en América Latina. En efecto, el lugar que les tocó ocupar en las distintas manifestaciones culturales (coloquios, debates, conferencias, exposiciones y publicaciones) ha sido insignificante por no decir nulo. En tal sentido, la expresión "encuentro de dos mundos" o su variante "encuentro de dos culturas" que, después de enconadas polémicas parece ser consensualmente admitida, cobra toda su significación.

Implícitamente es la confirmación de que la presencia negra en América Latina se percibe, de modo general, como un error de la historia; en todo caso comoalgo no genuino, como algo que no forma parte de la idiosincracia latinoamericana. En esto tal vez radique la predisposición de amplias capas sociales a ocultar, o a considerar sus rasgos negroides como una lacra. En Puerto Rico, por ejemplo, la exaltación de la triple articulación de la cultura "boricua" constituida por el aporte de los taínos, los negros y los blancos, se acompaña paradójicamente de un comportamiento social que, en última instancia, condena la herencia negra:

Muchos puertorriqueños temen que sus compatriotas vean en ellos rasgos raciales que la gente asocia mentalmente con los negros. Por eso muchos con rasgos somáticos de blanco, pero con una patente ascendencia racial negra, se consideran como que tienen "raya" escondida y con frecuencia son objeto de burla ${ }^{8}$.

7. Miguel Rojas Mix, Cultura afroamericana, de esclavos a ciudadanos (Madrid: Anaya, 1988) 102.

8. Rafael Falcón, «El tema del negro en el cuento puertorriqueño», en el número especial de Cuadernos Hispanoamericanos, 451-452 (enero-f ebrero, 1988) 97. 
La herencia biológica negra no es valorada sino que es vivida como un trauma, una mácula que se debe ocultar. Lointeresante es que el sesgo que consiste en "esconder sus rayas", supone al mismo tiempo otra predisposición a desenmascararlas.

La denegación de la herencia de los negros es tan fuerte que asoma incluso en la manera en que se les suele designar. Lo vemos en el concepto de la "morenada", que es particularmente vigente en el cono sur y en Chile. Pondré el ejemplo de este último país, donde:

Tanto se ha acostumbrado a decir que alguien es muy morenito, que ya nadie cree que hubo algún día negros. Negro es un color y se entiende como una raza, mientras que moreno es lo que tira a negro sin serlo. El diccionario dice que "es el menos claro de la raza blanca"9.

Llegados a este punto convendría preguntarmos sobre lo que tanto en el vivir como en las categorías mentales de los latinoamericanos fundamenta el rechazo consciente o no de la herencia negra, la dificultad de considerar a los negros como sujetos latinoamericanos. Mi hipótesis es que, pese a las apariencias y a cierta demagogia, a los negros se les sigue percibiendo fantástica y fundamentalmente como unos extranjeros.

Procuraré ahora asentar mejor esta hipótesis apoyándome en las pesquisas del antropólogo francés Claude Meillassoux. En Anthropologie de l'esclavage (1986), tomacomo base de reflexión la definición siguiente de E. Benveniste, que, como se verá, podría confortar mi propia hipótesis:

A partir de un análisis semántico, E. Benveniste, descubre "los orígenes sociales del concepto de libre". El sentido primario, no es como se pudiera imaginar "sacarse de algo", es por el

9. Rojas Mix, 63-64. 
contrario la pertenencia a una matriz étnica designada por una metáfora de crecimiento vegetal. Esta pertenencia confiere un privilegio que ni el extranjero ni el esclavo tienen. El extranjero es al contrario, el que no se ha desarrollado en el medio social donde se encuentra, el que no creció en la concatenación (entrelacs) de las relaciones socio-económicas que sitúan a un hombre con respecto a todos los demás ${ }^{10}$.

Se me podrían objetar dos aspectos. Primero, la aplicación mecánica de unas conclusiones antropológicas sobre la cuestión negra en América Latina. Segundo, el mal uso de estas mismas conclusiones: Meillassoux las maneja en ef ecto para el análisis de lo que él llama la sociedad doméstica (distinta en su lógica de la sociedad nacional). Sin embargo, pese a esas reservas, me parece que el análisis de Benveniste pudiera aplicarse a la situación de los negros en América Latina. Caben, en efecto, dentro de las dos categorías discriminadas mencionadas en la cita: esclavos (hasta la abolición efectiva de la esclavitud) y extranjeros (en la época actual). Por otra parte, es preciso notar que Benveniste describe en realidad el funcionamiento de cualquier representación ideológica determinista. En el caso que nos ocupa, sería por ejemplo la "irremisible" mancha original que llevarían todos los negros.

Por lo cual, cualquier tentativa para demostrar que los negros, salvo sus antepasados, "crecieron en la concatenación de las relaciones sociales y económicas" latinoamericanas está de antemano condenada al fracaso. De hecho, América Latina en su gran mayoría se representa exclusivamente como una "matriz étnica común" resultante de la articulación de la herencia del indio y del español.

El impacto de seme jante constructo ideológico es tan fuerte que sus huellas se detectan en las declaraciones y producciones de los

10. Claude Meillassoux, Anthropologie de l'esclavage, le ventre de fer et d'argent (Paris: PUF, 1986) 23, traducción mía. 
intelectuales latinoamericanos. En su libro cuyo título ya de por sí es revelador, Formación de una cultura nacional indoamericana, el escritor y antropólogo peruano José María Arguedas, define en estos términos la fusión fundadora de lo que él considera la identidad peruana:

Es inexacto considerar como peruano únicamente lo indio: es tan erróneo como sostener que lo antiguo permanece intangible (...) Durante siglos, las culturas europeas e indias han convivido en un mismo territorio en incesante reacción mutua influyendo la primera sobre las otras con los crecientes medios que su potente e incomparable dinámica le of rece; $y$ la india defendiéndose y reaccionando gracias a que su ensamblaje interior no ha sido roto y gracias a que continúa en su medio nativo ${ }^{11}$.

Cada uno apreciará las contradicciones de una declaración que coloca de entrada a las culturas indias en posición de inferioridad, que exalta el papel necesariamente fecundador de las culturas europeas. Lo que interesa a mi propósito es recalcar que los negros por su condición de extranjeros - tal es mi hipótesis- quedan así lógicamente fuera de este "entre nosotros" (blancos + indios), fuera de esa fusión original que reivindican los países latinoamericanos. Es más, se les representan a menudo como un peligro, una amenaza a esa misma fusión.

Según mi propia lectura, esa percepción es la que transcribe la tercera novela de Arguedas, El sexto (1979). En esta novela, la cárcel que constituye el espacio novelesco central, es al mismo tiempo una metáfora de la sociedad peruana, amenazada por la presencia del persona je negro. Este en ef ecto es representado como la encarnación del Mal: no sólo comunica un saber diabólico a sus acólitos sino que

11. José Maria Arguedas, Formación de una cultura nacional indoamericana (México: Siglo XXI, 1975) 2. 
se distingue por su violencia "irracional" y por su decadencia lúbrica. Manifiesta de hecho una propensión (retratada como enfermiza) a sodomizar ciertos prisioneros. Su decadencia está, por otra parte, potenciada por el tamaño desproporcional y "anormal" de su pene.

Si nos referimos a lo que afirma Denys Cuche, esta deformidad que se pinta en $\mathrm{El}$ sexto, resulta entonces ser la transcripción de un mito profundamente grabado en el imaginario social de los peruanos: el mito del negro todo-sexo y lascivo por antonomasia:

El estereotipo del negro sexualmente potente ha marcado profundamente el inconsciente peruano (...) Esas ideas se asocian espontáneamente a la imagen del Negro físicamente vigoroso, violento, fanático, sin moralidad, etc. ${ }^{12}$.

Queda por considerar un elemento semiótico importante que determina al personaje del negro en El sexto y que nos parece revelador: no tiene nombre. Esta ausencia es tanto más cargada de sentido cuanto que el nombre es lo que permite el anclaje en una "comunidad" nacional o étnica determinada. En otras palabras, el nombre es un signo de pertenencia y de reconocimiento social.

En este sentido, pudiérase legítimamente postular que no hubo, en los esquemas mentales de los peruanos, una real ruptura con respecto al período de la esclavitud. Porque en aquel momento los negros, aparte de su designación genérica ("piezas de indias", "carabalíes", "congos", "locumés", "sacos de carbón", etc.), no tenían nombre; llevaban, en realidad, como nombre, el símbolo o la marca de la propiedad a la cual estaban amarrados jurídicamente. Al contrario de los indios, los negros no eran sujetos del Perú virreinal sino de sus amos. Sea como fuere, el estatuto de que gozaban era ante todo el de instrumento útil. Sólo durante su manumisión era cuando podían,

$\overline{12 .} \quad$ Denys Cuche, Le Pérou négre (Paris: L'Harmattan, 1981) 120, traducción mía. 
hasta cierto punto, valerse de las disposiciones legales previstas para los negros "libres".

Este rápido análisis nos permite afirmar que en la novela de Arguedas nos enfrentamos, mediante el personaje del negro, con la cuestión de la descalificación de los negros en tanto latinoamericanos. Losque han leído El sexto coincidirán conmigo que, porsu "monstruosidad", el destino fatal del persona je negro era su eliminación física.

Pues bien, no es mi propósito discutir las múltiples y crueles consecuencias sociales de dicha descalificación (prejuicios, segregación social, autodevaluación o sobrevaloración de sí, angustia obsesional, miedo, etc.). Quisiera, sin embargo, evocar un terreno donde esta misma descalificación se materializa: quiero hablar del campo de las investigación en ciencias sociales.

Pese a los considerables esfuerzos desarrollados (en Brasil y en Cuba principalmente), la mayor parte de las investigaciones sobre los negros se han interesado preferentemente por su folclor, sus presuntas psicología y patología diferenciales. Al margen de esto, puede afirmarse sin riesgo que pervive, en la investigación científica latinoamericana, una tremenda ausencia de los negros como productores o como objeto de estudio. Tal ausencia es tanto más significativa cuanto que, como bien lo señaló P. Bourdieu, la educación, íntimamente ligada a la investigación científica, es un sistema complejo que supone una definición social del saber, de lo que merece ser enseñado y aprendido, y de los que están autorizados a comunicarla ${ }^{13}$.

La investigación de la presencia negra (su cultura actual, su historia cotidiana, sus diversas producciones y sus luchas presentes) no parece constituir una prioridad, algo significativo para muchos investigadores latinoamericanos. Guillermo Bonfil Batalla nos trae indirectamente la prueba de ello cuando describe la ruptura que, segúnél, tuvo lugar hace poco en las ciencias sociales en América Latina. Dice:

13. Ver, entre otros estudios, Ce que parler veut dire (Fayard, 1982); Homo academicus (De Minuit, 1984). 
Las ciencias sociales en América Latina se han dedicado, en los últimos años, a un proceso de autorrevisión, de un análisis crítico de su pasado inmediato, de su situación actual y de sus perspectivas a corto o largo plazo... (un grupo de jóvenes sociólogos) luchan por una selección de temas de investigación donde el criterio fundamental sea la importancia del asunto en términos de la problemática actual de los países sudamericanos ${ }^{14}$.

Sería arriesgado ver en la patente ausencia de preocupación científica por los negros en el campo científico de América Latina, la prueba de que no representan "una problemática actual". Mi intención no es echarles la culpa a los investigadores que, a menudo, están confrontados con los múltiples requisitos de su propio campo; además, su trabajo queda fuertemente condicionado por cierta orientación global de las investigaciones que, por varias razones, llega a imponerse en los países en un momento dado.

Se trata más bien de recordar que, contrariamente a lo que se pudiera pensar, el campo científico (a pesar de sus especificidades) no está fuera de la dinámica social ${ }^{15}$.

En este sentido, la sociocrítica, al cuestionar la división del trabajo intelectual y las categorías tradicionales de la crítica, hace resaltar las ambigüedades, las contradicciones sociales del campo científico del cual todos participamos. Aparece así (siempre cuando sus postulados materialistas sean reafirmados)como una onda de choque contra el conjunto de pulsiones repulsivas, de prejuicios, de ficciones-

14. Guillermo Bonfil, «Del indigenismo de la Revolución a la antropología crítica», en De eso que llama antropología mexicana (México: Nuevo Tiempo, 1970) 39-65.

15. Apunta Denys Cuche algo que nos parece sintomático de esta determinación social del campo científico: "Todo el mundo conoce el Perú de los Incas y el Perú de los conquistadores, pero ¿quién conoce el Perú negro? Es más, entre los numerosos viajeros atraídos por el Perú, ¿quién sabe que existe en este país una minoría afroamericana que constituye una comunidad original? Aun entre los científicos investigadores, ¿cuáles son los que analizan hasta qué punto esta comunidad ha desempeñado un papel importante en la formación de la sociedad peruana? (...) Cabe reconocerlo, hasta ahora la minoría étnica negra no ha llamado mucho la atención de los especialistas en ciencias sociales", Denys Cuche, 9 , traducción mía. 
refugio, de alambrados mentales que excluyó y sigue excluyendo al negro del logos (latinoamericano o universal).

En todo caso, el estudio de los negros de América Latina cobrará legitimidad científica y se beneficiará de cierto crédito cuando sean realmente aceptados y reconocidos como plenos sujetos latinoamericanos. Sin este reconocimiento, cualquier investigación sobre ellos corre el riesgo de estar de antemano condenada a ocupar un lugarmarginal en los distintos campos de la producción intelectual latinoamericana.

El objetivo a corto o largo plazo sería obrar para que la herencia negra fuese aceptada como intrínsecamente constitutiva de lo que sería la Identidad latinoamericana. Es esta ineludible verdad que nos recuerda el escritor colombiano, Manuel Zapata Olivella en su libro Changó el Gran Putas. Dice:

Deja que Elegba el abridor de caminos, te revele tus futuros pasos ya escritos en las Tablas de Ifá, desde antes de nacer. Tarde o temprano tenías que enfrentarte a esta verdad: la historia del hombre negro en América es tan tuya como la del indio o la del blanco que lo acompañarán a la conquista de la libertad de todos $^{16}$.

16. Manuel Zapata Olivella, Changó el Gran P utas (Bogotá: Letras Americanas, 1992) 57. 